\title{
AN EXCEPTIONALLY WELL-PRESERVED SCORPION FROM THE BESANO FORMATION (MONTE SAN GIORGIO, MIDDLE TRIASSIC, SOUTHERN ALPS): PRELIMINARY STUDY
}

\author{
$\underline{\text { Marco Viaretti }}{ }^{1}$ (i), Gabriele Bindellini ${ }^{1}$ (D) \& Cristiano Dal Sasso ${ }^{2}$ (i) \\ ${ }^{1}$ Università degli Studi di Milano, Dipartimento di Scienze della Terra "A. Desio", via Mangiagalli 34, Milan, Italy; \\ gabriele.bindellini@unimi.it \\ ${ }^{2}$ Museo di Storia Naturale di Milano, Sezione di Paleontologia dei Vertebrati, Milan, Italy. cristiano.dalsasso@comune.milano.it
}

\section{KEYWORDS: Arachnida; Scorpiones; Triassic; Besano Formation; Monte San Giorgio.}

\section{Bullet-Points Abstract}

- Specimen BES SC 1973 represents the first record of an arachnid from the Besano Formation.

- Taphonomy and limb position indicate that the fossil is a scorpion carcass.

- Preservation is exceptional, structures such as trichobothria and median eyes are visible.

- The fossil was examined through stereomicroscopy under natural and UV light, and through SEM.

- A taxonomic study is currently undergoing.

\section{INTRODUCTION}

We introduce a preliminary study of specimen BES SC 1973 (Fig. 1), an exceptionally well-preserved fossil scorpion from the Besano Formation (Anisian/ Ladinian boundary). The fossil comes from the Sasso Caldo site, located on the NW slope of Monte Pravello, between Besano and Porto Ceresio (N. Italy). BES SC 1973 is composed of two parts, the carcass and its counterpart; it comes from the upper part of the outcrop, dated as earliest Ladinian (Bindellini et al., 2019). This contribution represents the first report of an arachnid from the Besano Formation.

The fossil record of Triassic scorpions is scarce. Only 38 Mesozoic valid species have been described, 9 from the Triassic (Dunlop et al., 2008; Dunlop, 2017). Given its exceptional preservation, specimen BES SC 1973 provides a novel and unique contribution to our understanding of scorpion evolution and paleobiology, increasing the number of Mesozoic scorpion taxa and the faunal composition of the Besano Formation.

\section{Materials AND Methods}

The first step was to discriminate if the specimen was an exuvia or a carcass. This has been performed through the morphological observation of the specimen, focusing in particular on the stance of the body and the relative position of the limbs. The body is stretched and shows just a slight bending on the metasoma; walking legs and pedipalps are retained close to the body. According to McCoy \& Brandt (2009), these criteria are enough to state that the specimen is a carcass.

After this first discrimination, we have taken photos of the fossil, with and without UV lights. Based on these, and on the observations through photos and stereomicroscopy, we have been able to describe its general anatomy. In general, the body shape is quite slender. The prosoma is not well-visible due to a partial overlap of the legs. However, the median eyes are incredibly well-preserved, as even internal structures can be distinguished (probably rhabdomeres), and traces of pigmentation are still present.

We have also produced a set of images using a SEM (JEOL JSM-5610LV) in BSE mode (back scattered electrons) on the counterpart. We have taken compositional images to discriminate remains of the cuticle and rock matrix, in addition to shadow images (a combination of compositional and surface images) to observe the depth of these structures.

\section{Discussions ANd Conclusion}

We recognized 7 segments in the mesosoma: this allows us to distinguish BES SC 1973 from the Paleozoic taxa, which have 8 mesosomal segments. The metasoma is composed of 5 well-preserved segments, which is the standard condition for the order Scorpiones. The telson is similar to Protobuthus

Corresponding autor's contact: marco.viaretti@studenti.unimi.it

How to cite: Viaretti et al. (2020). An exceptionally well-preserved scorpion from the Besano Formation (Monte San Giorgio, Middle Triassic, Southern Alps): preliminary study. Fossilia, Volume 2020: 53-55. https://doi.org/10.32774/ FosRepPal.2020.0614 

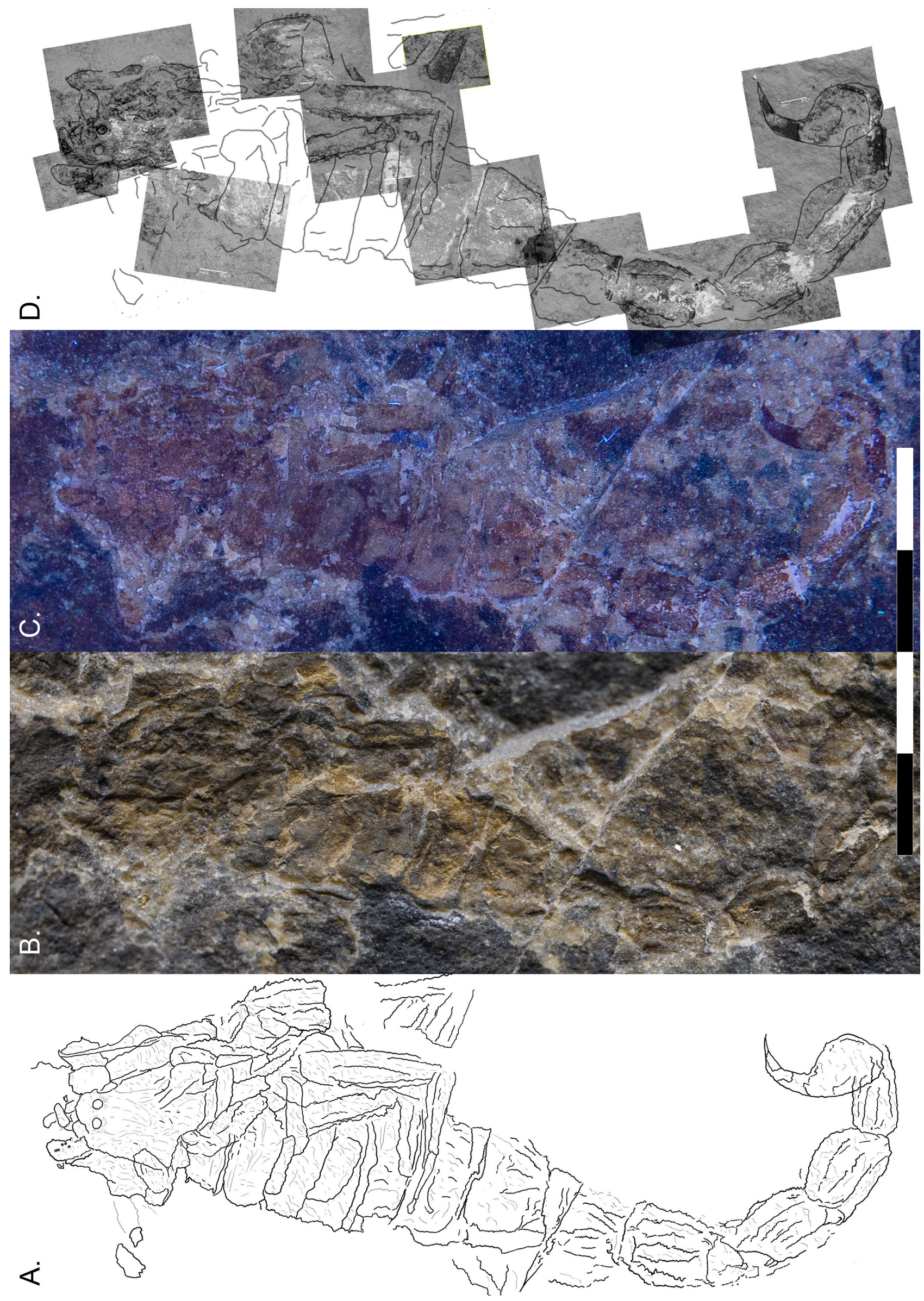
Fig. 1. Specimen Bes SC 1973, an indeterminate scorpion from the Middle Triassic of Monte San Giorgio. A. Interpretative drawing. B. Classic photo. C. UV photo. D. Collage of SEM images taken in BSE mode. Scale bar $=2 \mathrm{~cm}$.

Laurenço \& Gall (2004), as it is made of a vescicle with an oval shape and a slender aculeus, longer than the vescicle; also, there is no trace of a subaculear tooth.

Thanks to SEM images, we have recognized several structures that were not visible through stereomicroscopy, such as elements of the pedipalp, in particular a chela and a putative part of patella and femur. In addition, the SEM analysis has allowed recognition of the left pedipalp femur, where five trichobothria are present. Furthermore, we have found some fragments close to the anterior margin of the prosoma; their anatomical position and morphology are consistent with chelicerae portions. SEM analysis also has highlighted some ornamentation features, such as carinae on the metasoma. Interestingly, there are also traces of color banding, mainly covering the metasoma; although through stereomicroscopy and SEM analysis these bands show a light and dark coloration, we do not have enough data to state that they match the original color ornamentation.

Given the exceptional preservation of these structures, the next future advance will be the taxonomic analysis of the specimen, with the aim to improve our knowledge of the Middle Triassic biodiversity, and the evolution and phylogeny of this arachnid order.

\section{REFERENCES}

Bindellini G., Balini M., Teruzzi G. \& Dal Sasso C. (2019), Ammonoid and Daonella zonation of the Sasso Caldo quarry (Besano Formation, Middle Triassic). Strati 2019, 3rd International Congress on Stratigraphy. ST2.4 Ammonoids in stratigraphy: Abstract book, p.87.

Dunlop J. A., Penney D., Tetlie O. E. \& Anderson L. I. (2008). How many species of fossil arachnids are there? Journal of Arachnology, 36 (2): 267-272.

Dunlop J. A., Penney D. \& Jekel D. (2019). A summary list of fossil spiders and their relatives in World Spider Catalog. Natural History Museum Bern, online at http://wsc. nmbe.ch, version 20.5, accessed on 08/10/2019.

Laurenço W. R. \& Gall J.C. (2004). Fossil scorpions from the Buntsandstein (Early Triassic) of France. Comptes Rendus Palevol, 3 (5): 369-378.

McCoy V. E. \& Brandt D. S. (2009). Scorpion taphonomy: criteria for distinguishing fossil scorpion molts and carcasses. Journal of Arachnology, 37 (3): 312-320. 